\title{
A integração das Unidades de Pronto Atendimento (UPA) com a rede assistencial no município do Rio de Janeiro, Brasil
}

Mariana Teixeira Konder(a)

Gisele O'Dwyer ${ }^{(b)}$

Konder MT, O'Dwyer G. The integration of the Emergency Care Units (UPA) with healthcare services in the city of Rio de Janeiro, Brazil. Interface (Botucatu). 2016; 20(59):879-92.

The launching of Emergency Care Units (UPA in Portuguese) was a prominent health policy in the city of Rio de Janeiro during recent years. The aim of this study was to examine UPAs' integration with other health services in order to assess their impact on the development of integrated healthcare networks. Nine interviews with state and local managers, UPAs' coordinators and primary care units' coordinators were performed. The data collected were interpreted under Giddens' Structuration Theory. UPAs presented a low level of integration with other healthcare facilities within local emergency care network, due to structural problems as well as managerial fragmentation. In spite of the political and financial investment, the strategy of the UPAs has not been able to overcome the low degree of integration among local health services. Moreover, primary care services remain a lower priority. Thus, UPAs have contributed in lesser extent to the development of integrated healthcare networks.

Keywords: Emergency medical services. Delivery of healthcare. Health services administration.
No município do Rio de Janeiro, a implantação das Unidades de Pronto Atendimento 24h (UPA) foi o fio condutor da política de saúde e modelo para estruturação da rede de urgência e emergência (RUE). Este estudo analisou a integração das UPAs na rede assistencial do município. Foram realizadas nove entrevistas, com gestores centrais e locais, analisadas à luz da Teoria da Estruturação de Giddens. Resultados mostraram pouca integração das UPAs, por deficiências estruturais da rede de serviços e fragmentação gerencial, pela ausência de governança unificada. Apesar do investimento político e financeiro, essa estratégia não logrou contornar os problemas de integração entre as unidades de saúde e, ainda, ressaltou a baixa prioridade governamental para a atenção básica. Assim, as UPAs pouco contribuíram para o desenvolvimento de redes de atenção à saúde e para a reorientação do modelo assistencial.

Palavras-chave: Serviços Médicos de Emergência. Atenção à Saúde. Administração de Serviços de Saúde.

\footnotetext{
(a) Programa de PósGraduação em Saúde Pública, Escola Nacional de Saúde Pública, Fundação Oswaldo Cruz (Ensp/Fiocruz). R. Leopoldo Bulhões, 1480, $7^{\circ}$ andar, sala 727, Bonsucesso. Rio de Janeiro, RJ, Brasil. 21041-210 marianakonder@ gmail.com

(b) Departamento de Administração e Planjeamento em Saúde, Ensp/Fiocruz. Rio de Janeiro, RJ, Brasil. odwyer@ensp.fiocruz.br
} 


\section{Introdução}

Na última década, o governo federal vem priorizando a organização da atenção às urgências no país ${ }^{1,2}$. Em 2003, foi inaugurada a Política Nacional de Atenção às Urgências (PNAU) ${ }^{3}$, cujo ineditismo repousava no olhar ampliado proposto para a questão. Essa política deu especial atenção à assistência pré-hospitalar e enfatizou a compreensão de que a atenção às urgências não está restrita ao hospital. Para isso, retomou a proposta de constituição de redes locorregionais de atenção às urgências com um componente pré-hospitalar fixo ${ }^{4}$, composto tanto pela atenção básica ( $A B$ ) como por unidades de pronto-atendimento não hospitalares, que constituiriam retaguarda para a primeira ${ }^{3}$. Documentos subsequentes instruíram implantação, financiamento e expansão desse componente, que viria a ser popularizado como Unidades de Pronto Atendimento 24h (UPA) ${ }^{5-8}$.

As UPAs surgiram, em 2007, no município do Rio de Janeiro, como iniciativa do governo do Estado, pretendendo responder ao contexto de crise na saúde do município que teve seu ápice em 2005'. A partir daí, as UPAs foram implantadas de forma bastante acelerada, primeiro na capital e, posteriormente, no restante do estado. Somente no final de 2008, houve a primeira portaria regulando as UPAs na esfera federal ${ }^{3,9}$. Dados da Coordenação Geral de Urgência e Emergência, de maio de 2011, mostravam o estado do Rio de Janeiro com 43 UPAs, seguido por Pernambuco e São Paulo com apenas 14 e 13 unidades respectivamente. De 2007 a 2012, foram construídas 31 UPAs na capital e trinta fora da capital ${ }^{9}$. Em 2015, o município tinha 32 UPAs, num total de setenta em todo o Estado. Atualmente, existem 398 UPAs no país e está prevista a construção de mais $889^{10}$. Estudo nacional recente aponta que a maioria das UPAs está em municípios com mais de um milhão de habitantes, seguidos por municípios com população entre quinhentos mil e um milhão, privilegiando regiões com melhores condições socioeconômicas e de oferta de serviços, como a região Sudeste ${ }^{11}$.

A cidade do Rio de Janeiro apresenta cenário peculiar, com uma rede de atenção básica (AB) em incipiente processo de expansão, devido à adesão tardia do município à Estratégia de Saúde da Família, e uma rede hospitalar fragmentada, pelos conflitos decorrentes da gestão dessas unidades serem responsabilidade de diferentes esferas administrativas ${ }^{12}$.

O destaque recebido pelas UPAs na política de saúde do município, aliado à pouca produção científica sobre este tema justificam o objetivo deste estudo de analisar a integração dessas unidades com a rede assistencial no município do Rio de Janeiro, procurando compreender seus possíveis impactos na reorientação do modelo assistencial.

A pesquisa apresentada neste artigo, oriunda de dissertação de mestrado, foi aprovada por Comitê de Ética em Pesquisa, conforme os princípios legais e éticos da Resolução nº 466/2012 do Conselho Nacional de Saúde.

\section{Métodos}

Esse estudo apoiou-se no referencial teórico apresentado por Anthony Giddens por meio da Teoria da Estruturação ${ }^{13}$, que propõe uma conciliação da oposição entre agente e estrutura. A partir do conhecimento de uma dada estrutura e de uma interpretação das consequências da ação, a partir do acesso ao agente, é possível compreender as práticas sociais. Da Teoria da Estruração foram utilizados os conceitos de estrutura e cognoscitividade do ator, abordada por meio da consciência discursiva. A estrutura é o conjunto de regras e recursos implicados de modo recursivo na reprodução social. Os agentes manipulam esses recursos enquanto estratégia de controle. O acesso à consciência discursiva permite compreender como os agentes aplicam seu conhecimento sobre a manipulação dos recursos a que têm acesso para reproduzir sua autonomia estratégica ${ }^{13}$. As práticas podem ser entendidas como continuidades de encontros mais restritos e presenciais (integração social) ou podem estabelecer conexões mais amplas no tempo e no espaço e não presenciais (integração sistêmica) ${ }^{14}$.

O SUS pode ser compreendido como um sistema social e, em menor grau, a rede de atenção às urgências pode ser observada também como um sistema social, em que os atores envolvidos estão aplicando recursivamente regras e recursos para a produção e reprodução de práticas sociais. Nesse 
caso, entende-se que a construção dessa rede de atenção às urgências se consubstancia pela ação dos agentes. Estes empregam regras e recursos, que estão envolvidos na geração de poder ${ }^{13}$. Contudo, ao mesmo tempo em que os atores fazem uso da estrutura (regras e recursos) para sua ação, também a estrutura impõe limites à ação. Assim, a estrutura é sempre tanto coerciva quanto facilitadora, em virtude da relação inerente entre estrutura e agência (agência e poder). Em outras palavras: a ação humana é ora facilitada, ora limitada pela estrutura social, a qual se encontra constantemente criada e recriada por meio da ação humana ${ }^{15}$.

Entendendo a rede assistencial e as políticas norteadoras como regras e recursos, conformando a estrutura, procurou-se realizar o mapeamento das regras, estruturas e processos que modulam ou influenciam a integração das UPAs com os demais componentes do sistema de saúde no município do Rio de Janeiro. Primeiramente, procedeu-se ao levantamento documental da produção normativa concernente à organização do sistema de saúde e da Rede de Urgência e Emergência (RUE) entre o período de 2007 a 2012. No âmbito federal, a produção normativa especificamente sobre as urgências e sobre as UPAs foi extensa, enquanto as normatizações estadual e municipal foram mais escassas e de cunho mais administrativo, compostas de atos normativos concernentes à implantação, início de funcionamento e gestão das unidades individualmente.

Para o acesso à consciência discursiva dos agentes, foram realizadas entrevistas com atores-chave para aprofundamento na dinâmica de coordenação entre as unidades de saúde. Para tal, foi selecionada uma região do município, a área programática (AP) 3.1, que aliou a conveniência derivada da facilidade de acesso ao número de UPAs existentes na região, segundo maior do munícipio (Tabela 1).

Tabela 1. Distribuição populacional e de UPAs por área programática, Rio de Janeiro/RJ, 2012.

\begin{tabular}{ccc}
\hline Área Programática & População (mil hab) & UPAs \\
\hline 1.0 & 297.976 & 0 \\
2.1 & 638.050 & 3 \\
2.2 & 371.120 & 1 \\
3.1 & 886.551 & 5 \\
3.2 & 569.970 & 2 \\
3.3 & 948.638 & 6 \\
4.0 & 909.368 & 2 \\
5.1 & 671.041 & 5 \\
5.2 & 721.773 & 3 \\
5.3 & 311.959 & 3 \\
Total & 6.320 .446 & 30 \\
\hline
\end{tabular}

Fonte: CENSO/IBGE, 2010 e CNES, 2012. Elaboração própria.

Nota: não contabilizada a UPA do complexo prisional de Gericinó.

Foram realizadas: duas entrevistas com gestores centrais, cinco entrevistas com coordenadores de UPAs e duas entrevistas com coordenadores de unidades básicas de saúde, totalizando nove entrevistas (Quadros 1 e 2). Estes atores encontravam-se em posições privilegiadas no sistema de saúde local e na rede de atenção às urgências, tendo, por isso, capacidade de prover informações cruciais sobre o funcionamento da coordenação entre essas diversas unidades e os fluxos de atendimento e cuidado efetivamente estabelecidos, tanto nos seus aspectos bem-sucedidos quanto nas suas dificuldades. Quanto aos coordenadores de unidades básicas, a seleção foi feita considerando-se a elevada cobertura populacional das respectivas unidades, próxima a 100\%, bem como a presença de UPA no território de atuação dessas unidades. 
Quadro 1. Relação das UPAs pesquisadas, Rio de Janeiro, 2012.

\begin{tabular}{|l|l|l|l|l|l|}
\hline \multicolumn{1}{|c|}{ UPA - AP 3.1 } & \multicolumn{1}{|c|}{ Maré } & \multicolumn{1}{c|}{ Ilha } & \multicolumn{1}{c|}{ Penha } & Manguinhos & Complexo Alemão \\
\hline Inauguração & $30 / 07 / 2007$ & $22 / 09 / 2008$ & $16 / 10 / 2008$ & $29 / 05 / 2009$ & $06 / 04 / 2010$ \\
\hline Esfera administrativa & Estadual & Estadual & Estadual & Municipal & Municipal \\
\hline Tipo administração & Direta & Direta & Direta & $\begin{array}{l}\text { Indireta } \\
\text { OS FIOTEC }\end{array}$ & $\begin{array}{l}\text { Indireta } \\
\text { OS IABAS }\end{array}$ \\
\hline Vínculo coord. médico & $\begin{array}{l}\text { contrato temporário } \\
\text { FIOTEC }\end{array}$ & $\begin{array}{l}\text { oficial CBMERJ } \\
\text { cedido a SES }\end{array}$ & $\begin{array}{l}\text { oficial CBMERJ } \\
\text { cedido a SES }\end{array}$ & $*$ & CLT \\
\hline Sistema de informação & Klinikos & Klinikos & Klinikos & Klinikos & VitaCare \\
\hline
\end{tabular}

Fonte: Elaboração própria.

Nota: * A UPA Manguinhos estava sem coordenador médico designado. A entrevista foi realizada com o gerente da unidade.

Quadro 2. Relação de entrevistados da pesquisa com o tempo de ocupação do cargo, Rio de Janeiro, 2012.

\begin{tabular}{|l|l|}
\hline \multicolumn{1}{|c|}{ Entrevistados } & Tempo no cargo \\
\hline Coordenador AB & 1 ano e 7 meses \\
\hline Coordenador AB & 2 anos e 4 meses \\
\hline Coordenador UPA & 1 ano \\
\hline Coordenador UPA & 1 ano e 3 meses \\
\hline Coordenador UPA & 9 meses \\
\hline Coordenador UPA & 4 anos e 2 meses \\
\hline Coordenador UPA & 3 anos e 8 meses \\
\hline Gestor central municipal & 3 anos e 8 meses \\
\hline Gestor central estadual & 8 meses \\
\hline
\end{tabular}

Fonte: Elaboração própria.

As entrevistas ocorreram entre junho de 2012 e janeiro de 2013, sendo orientadas por roteiros semiestruturados desenvolvidos para gestores do nível central, coordenadores de UPA e de AB. Esses roteiros foram elaborados considerando-se os atributos preconizados pela OPAS ${ }^{16}$ para se desenvolverem redes integradas de serviços de saúde. Todos os entrevistados assinaram Termo de Consentimento Livre e Esclarecido. Na análise das entrevistas, adotaram-se procedimentos de decomposição e distribuição temática, visando identificar elementos recorrentes, visões comuns e divergentes entre os entrevistados. Para compreensão da integração das UPAs na rede foram considerados os seguintes tópicos: o funcionamento das UPAs e sua relação com outros componentes da RUE, o papel das UPAs na RUE e a dinâmica da rede. 


\section{Resultados e discussão}

Nessa seção, apresenta-se a análise das falas dos entrevistados, incluindo caracterização da estrutura e dos agentes envolvidos. Segue-se discussão das relações entre estrutura e agente, segundo a Teoria da Estruturação de Giddens.

\section{As UPAs e seu funcionamento}

As UPAs funcionam todos os dias da semana, 24 horas por dia, atendendo a todos os usuários que buscam a unidade, desenvolvendo acolhimento e classificação de risco de forma regular. A institucionalização da classificação de risco encontrou dificuldades como: o conflito gerado pela falta de compreensão por parte dos usuários acerca do modo de organizar o atendimento; a heterogeneidade dos protocolos de classificação de risco, com modificações dos estratos, havendo subdivisões ou inclusão de outros critérios, como a idade; e o envolvimento predominante do profissional de enfermagem, com pouca participação do médico. No perfil de atendimento das UPAs, predominaram os pacientes de baixo risco, embora a implantação heterogênea do protocolo limite a extrapolação desse resultado.

As UPAs funcionam com sistema de prontuário eletrônico, permitindo registrar todas as etapas do atendimento ao usuário. Foi observada variabilidade dos sistemas de informação utilizados, potencial obstáculo, pela incompatibilidade de softwares entre diferentes unidades, à compilação das informações e à posterior ampliação da informatização na rede. A melhoria no registro dos atendimentos foi um aspecto positivo. No entanto, os dados disponíveis (tempos de espera para atendimento, taxa de ocupação das unidades e problemas de saúde mais incidentes) são mais utilizados pelo nível central do que na gestão local das unidades.

Pacientes nas UPAs que necessitem de hospitalização são regulados por meio de diferentes canais. Nas UPAs geridas pelo estado, vagas de enfermaria eram solicitadas pelo sistema online de regulação (SISREG), sistema que regula as vagas da Central Municipal de Regulação (CMR) de leitos; e vagas de UTI eram solicitadas diretamente à Central Estadual de Regulação, por meio de núcleo interno exclusivo para as UPAs do Estado, denominado CEMUPA. As UPAs municipais relacionavam-se apenas com a CMR, por meio do SISREG.

As UPAs também solicitam realização de exames complementares de maior complexidade ou avaliações de especialistas, via SISREG, quando necessário para definir o diagnóstico ou para a continuidade do tratamento de pacientes ainda aguardando vaga hospitalar nas UPAs. Os exames disponíveis são: tomografia computadorizada, ultrassonografia e ressonância magnética. O mesmo se aplica à realização de hemodiálise e hemotransfusão nas condições acima descritas. Para tal, fica previsto um fluxo de interação com as emergências hospitalares por meio da $C M R$, quando as necessidades do paciente extrapolam a capacidade de cuidado da UPA.

\section{Relação com a Atenção Básica}

Embora as UPAs tenham como competência ser retaguarda para a $A B$, o cotidiano dessas unidades é bem diferente. Essa função de apoio só é claramente reconhecida em relação aos horários em que as unidades básicas não funcionam. A competência de funcionar como apoio para exames complementares ou para leitos de observação não está bem estabelecida e não ocorre de maneira formalizada. Em alguns casos, as UPAs sequer reconhecem a possibilidade de desempenharem esse papel.

“[...] existe aquele paciente que sabe que o seu caso é pra Posto [de Saúde], mas não tem condições de ir ao Posto porque é final de semana ou à noite. Tá. Então, ele está no lugar certo [na UPA]". (gestor estadual) 
No período diurno, em que ambas as unidades estão funcionando, não há formato de comunicação/interação determinado. Não existem fluxos formais para referenciar pacientes da $A B$ para as UPAs, nem mecanismos facilitadores do acesso às UPAs de paciente previamente avaliados na $A B$. O caminho contrário é igualmente mal definido.

“[...] é uma coisa extraoficialmente [...]. Não [há fluxo formalizado entre UPA e Atenção Básica]. Quando eles estão lá no sufoco eles ligam. Eles têm mesmo um fluxo com a UPA do município, com as unidades do município, não com as do estado... Mas aí, a gente acaba ajudando". (coordenador UPA)

"O encaminhamento é a guia de referência. [...] A gente não consegue fazer nada pelo SISREG. Não consegue cadastrar consulta eletiva, nada. Só [solicitar] internação mesmo". (coordenador UPA)

"[...] conta-se com a UPA que é com quem a gente deveria contar como suporte de maior peso, fica muito falho. As relações, elas existem, só que muito falhas". (coordenador $A B$ )

$A A B$, muitas vezes, não se considera capaz de acolher a demanda espontânea diante de tantas tarefas já estabelecidas. Em outros casos, aponta deficiência de qualificação ou estrutura para atender casos urgentes, não dispondo de medicações e exames complementares adequados para esses casos.

\section{Relação com o SAMU}

As UPAs também devem fornecer retaguarda para pacientes atendidos pelo Serviço de Atendimento Móvel de Urgência (SAMU). No entanto, no município do Rio de Janeiro, encontramos uma compreensão um pouco diferente, além de uma relação muito frágil entre estes componentes da RUE. As UPAs sob a esfera administrativa estadual indicam ser referência para recebimento de pacientes atendidos pelo SAMU apenas nos quadros clínicos de dor torácica. Além disso, o SAMU funciona dentro da esfera administrativa estadual, não desenvolvendo relação com a rede municipal.

“O SAMU é atendimento em casa. Não tem nada a ver com UPA, é atendimento em casa. [...] Hoje, no Estado, o SAMU regula paciente para o hospital". (gestor estadual)

"Não [temos relação com o SAMU]. SAMU não faz contato. Com a gente não. Chegam de supetão! Gera conflito? Gera conflito". (coordenador UPA)

"A gente não recebe paciente do SAMU. Mas pode acontecer esporadicamente de a gente receber alguns que estejam com dor torácica, ou o paciente instabilizando no meio do transporte". (coordenador UPA)

A gestão municipal tem, assim, sua própria Central de Ambulâncias para atender às necessidades de remoção entre suas unidades. Apesar de UPA e SAMU serem serviços de atendimento préhospitalar e de as portarias ministeriais indicarem articulação entre eles, a ponto de vincularem a expansão do primeiro ao segundo, não é o que acontece na prática.

"No caso aqui da cidade do Rio de Janeiro quando o SAMU foi instituído a Prefeitura não quis o SAMU, então, o estado tomou pra si o serviço e instituiu o serviço na cidade do Rio de Janeiro. Então, o SAMU é estadual. É do Governo do Estado. Não é da Prefeitura. [...] E, com isso, a gente precisa de transporte inter-hospitalar e esse serviço a gente terceiriza pra duas empresas". (gestor municipal) 
O contato é focalizado e os serviços são independentes. A condição de retaguarda para o SAMU, como apresentado nas portarias, se expressa de forma frágil no cotidiano, sendo reconhecido nas falas com evidente resistência.

\section{Relação com os hospitais e a central de regulação}

A retaguarda hospitalar tem sido fonte de grande dificuldade para o trabalho nas UPAs. O acesso aos leitos é considerado difícil tanto pela insuficiência numérica quanto pela dificuldade de interação com os hospitais.

"A dificuldade é a retaguarda. Retaguarda de tudo. A retaguarda, principalmente, de enfermaria e terapia intensiva. [...] O que acontece é que a gente ainda não tem na cidade o quantitativo de leitos ideal de retaguarda, pelo menos, regulados". (gestor municipal)

"A nossa maior dificuldade hoje na UPA é a porta de saída. É a maior dificuldade, porque você atende o paciente... Seja a porta de saída em todos os sentidos. Seja o paciente que precisa ir pra CTI, ou que precisa da enfermaria". (gestor estadual)

A existência de hospitais de referência para as UPAs é clara na esfera estadual, ainda que um mesmo hospital seja referência para muitas unidades. Na esfera municipal, todas as UPAs municipais têm o acesso aos hospitais intermediado pela central de regulação. Do conjunto das falas, podese perceber um cenário complexo em que gestores centrais e locais exprimem percepções pouco convergentes. Tanto na interação com os hospitais quanto com a central de regulação, os gestores centrais tendem a delinear um panorama mais otimista.

"O acesso é fácil porque todos os leitos são regulados. Pelo menos, no município do Rio, 100\% dos leitos de enfermaria são regulados e estão na Central de Regulação. [...] A Central de Regulação funciona muito bem e tem um papel preponderante". (gestor municipal)

"Com relação aos hospitais, a relação está ficando muito melhor mesmo! Existe um feedback dos diretores com as UPAs". (gestor estadual)

"Se a gente tivesse um suporte de algum hospital que garantisse algumas vagas pra gente seria melhor, mas a gente não tem isso". (coordenador UPA)

A relação com a central de regulação é lenta e distante, majoritariamente via comunicação online, e apenas em casos mais graves, os chamados vaga zero, via chamada telefônica. Assim, a central de regulação é percebida como um obstáculo entre as UPAs e os hospitais. Isso é mais evidente no caso das UPAs municipais, em que o contato via CMR tornou-se o único fluxo formal de acesso ao hospital.

“[...] a gente tinha uma relação muito estreita com o [hospital] Getúlio Vargas no sentido de conseguir algumas tomografias, algumas avaliações de cirurgias sem seguir a Central, mas isso foi proibido. Só pela Central. Aí teve que parar com esse tipo de contato, porque estava sobrecarregando e não sei o que... Tem que seguir direitinho a Central". (coordenador UPA)

“Eu acho que eles [da central de regulação] têm cotas pra poderem liberar, no mínimo, um número de vagas por cada unidade porque, senão, depois eles podem ser questionados a respeito disso". (coordenador UPA)

Essa percepção da central de regulação como barreira é apontada em outro estudo, que também implica a fragmentação da rede assistencial na pouca efetividade das práticas nas centrais de 
regulação. Dependentes de mecanismos não formais de ação, fluxos paralelos de contatos pessoais são a ação cotidiana da regulação ${ }^{17}$.

No todo, percebe-se que a rede hospitalar é autônoma e fragmentada, tendo os gestores, mesmo os centrais, conhecimento incompleto desta rede. Uma oposição entre esfera municipal e estadual explica as relações preferenciais com os hospitais. Um dos resultados é que pacientes necessitando de hospitalização permanecem nas UPAs aguardando vaga por períodos superiores a 24 horas, sistematicamente. Nacionalmente, o quadro é o mesmo ${ }^{11}$ : apenas 1,7\% do total de atendimentos das UPAs compreendem casos de alto risco, porém, esses pacientes não encontram adequada resposta na retaguarda hospitalar. A inexistência de vagas, principal causa de "internação em UPA", explica a permanência dos pacientes por mais de 24 horas nessas unidades, conforme pesquisa nacional ${ }^{11}$.

O componente hospitalar ilustra mais incisivamente o papel negativo da distribuição diferencial dos serviços de saúde entre as três esferas administrativas. Não há unificação real dos leitos na central municipal de regulação, como pode ser observado pela existência da CEMUPA. A regulação de leitos hospitalares é bastante frágil e fica esgarçada entre as esferas administrativas, acentuando a dificuldade de acesso aos hospitais.

\section{Papel das UPAs na RUE}

A criação das UPAs no município do Rio de Janeiro derivou de iniciativas estadual e municipal, não concomitantes, mas convergentes. O governo municipal justifica investimento neste mesmo modelo também como resposta às necessidades e carências das regiões menos favorecidas.

"O que a gente tentou aqui pensar pra montar? Carência de mobília de Saúde na região, distância entre os hospitais de Urgência e Emergência e a população. Onde tinham mais vazios sanitários, essa foi a opção. [...] Então, no todo, foi feito um estudo, meio que um georreferenciamento. A gente olhou a cidade toda, mapeou a cidade toda, viu toda a parte populacional, viu todos os [equipamentos] sanitários, viu o quantitativo populacional e o perfil da população, o perfil epidemiológico da população, a vulnerabilidade da população dentro desse perfil epidemiológico pra montar ou mobiliar de UPA aquela região". (gestor municipal)

Outro argumento apresentado na justificativa dessa estratégia, sobretudo no caso do governo estadual, foi a sobrecarga das emergências hospitalares.

"Acho que é um ganho pra população, ela acaba dando uma blindada na porta de entrada dos hospitais de emergência e acaba funcionando mesmo como uma unidade intermediária entre a Atenção Básica e a Rede de Urgência Hospitalar". (gestor estadual)

“Tem que ter UPA. É fundamental pra população. Desafoga os hospitais? Desafoga os hospitais". (coordenador UPA)

A estratégia é considerada importante e benéfica para a população, apesar dos problemas identificados, sobretudo na relação com os hospitais. No entanto, os depoimentos desses mesmos atores evidenciam que, na prática, a UPA vem ocupando um espaço um pouco diferente na rede de atenção à saúde.

"A demanda reprimida. Hoje a gente tem um atendimento que se você chegasse no posto e marcasse pra daqui a dois ou três meses, o paciente ia pra lá. Você acaba tendo o paciente que procura a UPA e não deveria, pois deveria estar no posto". (gestor estadual)

"A gente tem que atender emergência e o que a gente acaba atendendo é Atenção Básica. A nossa demanda é grande, porque a gente continua fazendo um trabalho que deixou de ser feito 
pela Atenção Básica de outros municípios e até do município do Rio. Então, gera uma demanda maior". (coordenador UPA)

"O perfil da UPA mudou, ele não é mais para dar suporte às emergências dos hospitais de grande porte, ele atende $90 \%$ de atenção básica. Hoje ele é um suporte da atenção básica, não mais das grandes emergências". (coordenador UPA)

“[...] muitos pacientes vêm aqui buscando soluções pros seus problemas ambulatoriais: dermatite, problemas ortopédicos crônicos, problemas reumatológicos crônicos, problemas ginecológicos, enfim, problemas que não deveriam ser abordados aqui". (coordenador UPA)

Em um município com adesão tardia à ESF e baixa cobertura da $A B$, não é surpreendente que se faça, por parte dos usuários, recurso à UPA na busca de solução para problemas considerados por profissionais e gestores como de natureza ambulatorial. A experiência das UPAs no município do Rio de Janeiro deu maior visibilidade a um problema latente: o déficit de pronto-atender. Assim, como indicado por seu alto volume de atendimentos e por terem perfil de atendimento predominantemente de baixo risco, mais do que aliviarem a sobrecarga das emergências hospitalares, as UPAs parecem estar acolhendo uma demanda reprimida, oriunda da insuficiência da atenção básica e da atenção ambulatorial especializada. Em outro estudo, um ambivalente papel também é identificado para as UPAs, em que a sistemática restrição à demanda dos usuários na esfera hospitalar vem legitimando as UPAs como portas alternativas às urgências hospitalares, secundarizando sua missão legal de compor um complexo assistencial vinculado à atenção básica ${ }^{11}$.

\section{Dinâmica da rede}

Aspecto importante da rede de urgências no município foi a relação entre as esferas administrativas. Na relação entre os componentes da RUE, foi recorrente a questão da diferenciação entre estadual e municipal e sintomática a ausência da esfera federal. Essa separação entre esferas governamentais é, portanto, característica essencial e condicionante da rede, claramente percebida nos discursos dos atores.

" $\mathrm{E}$, fora isso, é a gente ser uma cidade que tem todos os três entes fazendo a mesma coisa ao mesmo tempo, então, a gente tem federal, municipal e estadual fazendo Urgência e Emergência, fazendo média complexidade, fazendo alta complexidade e ninguém na realidade faz nada ou cada um faz o que tem que fazer e faz muito pouco". (gestor municipal)

"Nessa questão da integração, como a gente é do Estado e a Atenção Básica é do Município, às vezes, não existe o encaixe direitinho". (gestor estadual)

A interferência que este aspecto produz na integração da rede de serviços também é reconhecida. No discurso dos gestores centrais, embora se reconheça essa característica como problemática, rejeitase que haja fragmentação da rede de atenção às urgências.

“Olha... Só não fragmenta porque a gente está muito junto. Toda construção da RUE foi feita em conjunto e a gente tem uma conversa muito próxima, a gente tá sempre tentando estar muito próximo porque vive os mesmos problemas, então, se a gente não somar, vai dividir. [...] Tem uma grande abertura de ambos os entes, tanto estadual como municipal e a gente tem acesso, a gente senta, a gente conversa, a gente tem fórum de discussão e, enfim, um apoia o outro". (gestor municipal) 
A relação entre as esferas municipal e estadual é apontada como próxima e convergente na construção da RUE. Mais uma vez, porém, o relato dos gestores locais difere, evidenciando uma realidade em que o recurso a soluções alternativas de integração, sobretudo baseadas nas relações pessoais, é o cotidiano de sobrevivência na rede.

\footnotetext{
"Em alguns casos, quando precisa de algum suporte melhor, você tenta o contato de quem sempre tem o conhecimento em algum lugar". (coordenador UPA)

"Os nossos médicos [...] eles conhecem, eles trabalham, eles conhecem chefes de equipe daquele dia em outros hospitais, [...] porque quando procura alguma coisa você já vai procurar quem você conhece. [...] Então tem uma coisa meio que informal. [...] Uma pactuação informal". (coordenador UPA)

"Até para conseguir vaga de internação a rede de conhecimento funciona melhor que o SISREG". (coordenador UPA)
}

Outro aspecto relevante da rede é o atendimento a uma demanda oriunda de outras regiões, que é apontada como fonte de sobrecarga em alguns casos. Esse fenômeno é conhecido no munípio do Rio de Janeiro em relação à sua região metropolitana ${ }^{12}$.

“Porque assim, hoje, a gente não atende só a nossa região, a gente atende muito mais do que isso. [...] Você atende muito paciente de fora da tua rede mesmo, fora da tua área". (gestor estadual)

"A nossa característica é que a gente atende muito mais paciente que não é da nossa AP". (coordenador UPA)

Assim, no município do Rio de Janeiro, temos uma rede de urgência e emergência confrontada com uma demanda acima de sua capacidade e muito fragmentada entre as esferas de governo. A rede parece contar com mecanismos de integração ainda precários, fazendo com que, no cotidiano, prevaleça o contato pessoal como recurso para resolução dos problemas.

"[As UPAs] Pouquíssimo integradas. Nem parcialmente nem não-integrada, mas as integrações que existem é mais pelo fato da gente ter algum conhecimento". (coordenador UPA)

Assim, as UPAs se inserem na rede de atenção à saúde do município do Rio de Janeiro reproduzindo a dinâmica já estabelecida: a de uma integração limitada entre os pontos de atenção à saúde, fortemente calcada nas relações interpessoais.

\section{As UPAs, a RUE e a Teoria da Estruturação}

Para o objeto deste estudo - a integração das UPAs na rede de atenção às urgências no município do Rio de Janeiro -, identificamos que a legislação existente e, posteriormente, produzida aliada ao financiamento disponibilizado pelo Ministério da Saúde (MS), evidenciando a prioridade para o tema, constituiu aspecto estrutural facilitador da construção da RUE. Ainda que o recurso financeiro não tenha sido disparador do processo de implantação das UPAs no município, certamente representou forte estímulo para a continuidade e expansão dessa estratégia. Da mesma forma, destacam-se a prioridade e a disposição dos governos estadual e municipal, com investimento político e financeiro, que sustentaram a expansão dessas unidades como fio condutor da organização dessa rede.

As três esferas governamentais envolvidas nesse processo demonstraram dispor tanto de recursos autoritários - recursos não materiais envolvidos na geração de poder -, quanto de recursos alocativos 
- recursos materiais envolvidos na geração de poder - para disparar e impulsionar a construção e expansão dessas unidades.

Importante destacar que o processo indutor, liderado pelo MS, inclui provisões para que as UPAs sejam implantadas simultaneamente à estruturação de uma rede de urgências, haja vista as exigências relativas à $A B$ e ao SAMU presentes na portarias ministeriais. Trata-se de uma regra fundamental na estruturação da rede, que busca o desenvolvimento mais equilibrado dos componentes da RUE, mas que é apenas parcialmente cumprida pelos atores. Por outro lado, merece comentário o investimento político e financeiro claramente desigual, da parte de todas as esferas, entre componente préhospitalar e hospitalar, pois ficou claro que a estrutura física insuficiente dos hospitais públicos é elemento fortemente coercivo à estruturação da RUE.

A implantação e a expansão das UPAs colocaram em evidência um problema no município do Rio de Janeiro: a fragilidade da atenção básica. Este nível de atenção, relegado no município por longo período, sofre de diversas mazelas e o processo mais recente de expansão intensiva ainda é insuficiente para seu fortalecimento. Nesse caso, a precariedade da $A B$ não constitui elemento propriamente coercivo à construção da RUE, mas à reconfiguração do modelo assistencial. Do ponto de vista da motivação política, a insuficiência da AB serviu de argumento para a expansão das UPAs, e, portanto, para priorização da implantação de uma política de saúde municipal e estadual que privilegia a urgência no desenvolvimento do sistema de saúde locorregional, em detrimento da própria $A B$.

Apesar da pouca institucionalidade de algumas regras e do peso de elementos coercivos à estruturação da rede abordados nessa discussão, é importante destacar que a estratégia das UPAs foi exitosa no processo de institucionalização de algumas ferramentas importantes, tanto para o funcionamento interno como para a atuação em rede dessas unidades. No caso da classificação de risco, mesmo considerando-se as dificuldades comentadas, ficou evidente que há grande apoio institucional à adoção e desenvolvimento dessa ferramenta. O processo de informatização também merece destaque, tanto pelo aspecto pioneiro, quanto pelo potencial de favorecer a estruturação da rede. Assim, a prioridade que essas ferramentas receberam na implantação e expansão das UPAs constituiu elemento facilitador da disseminação desses recursos na rede. É importante salientar que as UPAs também representaram uma ampliação do acesso dos usuários a consultas médicas e exames complementares, sobretudo, em casos de menor complexidade.

É premissa desse estudo que redes de atenção à saúde são "organizações poliárquicas de conjuntos de serviços de saúde, vinculados entre si por uma missão única, por objetivos comuns e por uma ação cooperativa e interdependente"18 (p. 2300). Fica, portanto, evidente que a efetiva construção de redes de atenção à saúde requer tanto o estabelecimento de integração social - reciprocidade de práticas entre atores em circunstâncias de copresença -, como o desenvolvimento de integração sistêmica - reciprocidade de atores ou coletividade de atores no tempo-espaço ampliado, fora de condições de copresença, conforme Giddens apresenta na Teoria da Estruturação ${ }^{13}$. Assim, as circunstâncias de copresença podem ser o contexto de uma unidade de saúde, como unidades básicas ou UPA, onde profissionais precisam interagir entre si e com os usuários na produção do cuidado. Também a interação e a reciprocidade de práticas precisam se estabelecer entre diferentes unidades e diferentes níveis de atenção à saúde. Nesse caso, atores ou coletividades, formados pelos mesmos profissionais e outros ainda, interagem fora de situações de copresença. As relações estabelecidades entre UPA e central de regulação ou entre UPA e hospitais são exemplo interessante da questão da integração sistêmica, em que atores ou conjunto de atores interagem por meios de comunicação específicos para construírem as práticas cotidianas de cuidado em saúde.

Essa pesquisa identifica que a integração sistêmica da RUE ainda se encontra em estágio muito incipiente, como os próprios atores reconhecem. Se, por um lado, a fragilidade da AB no município, que não consegue ocupar a posição de coordenação da demanda na rede, acaba "empurrando" essa função para as urgências; por outro, a divisão da gestão dos estabelecimentos da rede de serviços entre as três esferas governamentais no município impõe dificuldades à constituição da RUE. Assim, no cotidiano, os atores vão produzindo práticas alternativas de integração, uma vez que as regras estabelecidas e os recursos disponíveis são insuficientes para a resolução dos problemas. O exemplo 
mais interessante dessas práticas alternativas é o recurso a uma rede de conhecimentos e contatos pessoais para contornar as dificuldades de integração e, muitas vezes, também, as dificuldades estruturais.

Os conceitos de integração aplicados nesta reflexão sobre redes remetem ao conceito de governança, discutido de modo muito criativo à luz da Teoria de Estruturação ${ }^{15}$ :

Se adotamos a metateoria social de Giddens para explicar os assuntos de governança, deduziremos que as interações entre atores sociais informados para a tomada de decisões estratégicas para as coletividades humanas (agência), em um espaço e tempo concretos, vão gerar as normas e recursos (estrutura) necessários para a implementação (ou não) das decisões adotadas e para tomada de decisões futuras; uma atividade social que recriará ou, em todo caso, modificará os elementos estruturais da governança. (p. 154 - tradução livre)

Este enunciado elucida como a criação e a inserção das UPAs, apesar de terem representado um elemento importante na estruturação da RUE, no período recente, não vieram acompanhadas de uma mudança na estrutura de governança da rede municipal. Com isso, apesar de se ter expandido a capacidade de atendimento, ampliando o acesso da população a diversos recursos, persistem dificuldades de acesso, sobretudo relacionadas à necessidade de interação entre diferentes serviços ou estabelecimentos. Fluxos e pactuações são frágeis, pouco conhecidos ou inexistentes. A percepção de uma rede fragmentada ficou muito evidente nas falas dos entrevistados, assim como uma grande valorização das ações dos agentes para contornar essa fragmentação, na forma de reuniões e contatos pessoais. Os gestores do nível central foram particularmente otimistas ao enunciar o efeito dessas ações, apontando para um cenário de avanço e aprimoramento de integração. Contudo, essas falas foram pouco condizentes com as realidades locais descritas pelos coordenadores das unidades.

\section{Considerações finais}

O cenário delineado pelos resultados desse estudo permite entrever que as regras postas não estão constituindo elementos suficientemente facilitadores da construção de uma rede de atenção à saúde, sobretudo, uma rede coordenada pela $A B$. Como observado, as UPAs vêm se ocupando de uma demanda majoritariamente de baixo risco que, em tese, seria melhor acolhida na $A B$, mas que acaba encontrando na UPA respostas mais imediatas. O resultado é cada vez menos prestígio e confiança na $A B$ e cada vez mais exames e procura por especialistas. Tampouco o processo de implantação das UPAs está modificando os modos de integração da rede. Isso fica evidente tanto nas dificuldades com a retaguarda hospitalar, quanto na resistência ao papel de retaguarda da $A B$.

Desse modo, podemos apontar que a prioridade que as UPAs têm recebido na política de saúde praticada no município, ao reforçar a lógica biomédica subjacente à estruturação da rede e competir por recursos e prioridade política com a $A B$, tem sido elemento insuficientemente facilitador da constituição de redes de atenção à saúde e, particularmente, restritivo à reorientação do modelo assistencial. 


\section{Colaboradores}

Mariana Teixeira Konder participou na concepção do artigo, elaboração da metodologia, obtenção e análise do material empírico e redação final do artigo; Gisele O'dwyer participou na concepção do artigo, elaboração da metodologia, análise do material empírico e redação final do artigo.

\section{Referências}

1. O'Dwyer G. A gestão da atenção às urgências e o protagonismo federal. Cienc Saude Colet. 2010; 15(5):2395-404.

2. Machado CV, Baptista TWF, Nogueira CO. Políticas de saúde no Brasil dos anos 2000: a agenda federal de prioridades. Cad Saude Publica. 2011; 27(3):521-32.

3. Portaria $n^{0} 1.863$, de 29 de setembro de 2003. Institui a Política Nacional de Atenção às Urgências, a ser implantada em todas as unidades federadas, respeitadas as competências das três esferas de gestão. Brasília (DF): Ministério da Saúde; 2003.

4. Portaria $n^{\circ} 2.048$, de 5 de novembro de 2002. Aprova o Regulamento Técnico dos Sistemas Estaduais de Urgência e Emergência. Brasília (DF): Ministério da Saúde; 2002.

5. Portaria $n^{\circ} 2.922$, de 2 de dezembro de 2008. Estabelece diretrizes para o fortalecimento e implementação do componente de "Organização de redes loco-regionais de atenção integral às urgências" da Política Nacional de Atenção às Urgências. Brasília (DF): Ministério da Saúde; 2008.

6. Portaria no 1.020, de 13 de maio de 2009. Estabelece diretrizes para a implantação do componente pré-hospitalar fixo para a organização de redes locorregionais de atenção integral às urgências em conformidade com a Política Nacional de Atenção às Urgências. Brasília (DF): Ministério da Saúde; 2009.

7. Portaria $n^{\circ} 1.601$, de 7 de julho de 2011. Estabelece diretrizes para a implantação do componente Unidades de Pronto Atendimento (UPA24h) e o conjunto de serviços de urgência 24 horas da Rede de Atenção àsUrgências, em conformidade com a Política Nacional de Atenção às Urgências. Brasília (DF): Ministério da Saúde; 2011.

8. Portaria $n^{\circ} 2.648$, de 7 de novembro de 2011. Redefine as diretrizes para implantação do Componente Unidade de Pronto Atendimento (UPA24h) e do conjunto de serviços de urgência 24 horas da Rede de Atenção às Urgências, em conformidade com a Política Nacional de Atenção às Urgências. Brasília (DF): Ministério da Saúde; 2011.

9. Lima LD, Machado CV, O'Dwyer G, Baptista TWF, Andrade CLT, Konder MT. Interdependência federativa na política de saúde: a implementação das Unidades de Pronto Atendimento no estado do Rio de Janeiro, Brasil. Cienc Saude Colet. 2015; 20(2):595-606.

10. Ministério da Saúde (BR). Sala de apoio à gestão estratégica [Internet]. Brasília (DF): MS; 2015 [acesso 2015 Jul 2]. Disponível em: http://189.28.128.178/sage/

11. Ibanez N. Os hospitais e a rede de atenção às urgências e emergências: desafios. Consensus Rev Cons Nac Secret Saude. 2013; 3(7):36-43.

12. Parada R. A construção do Sistema Estadual de Saúde: antecedentes e formas de inserção. Physis. 2001; 1(1):19-104.

13. Giddens A. A constituição da sociedade. 3a ed. São Paulo: Martins Fontes; 2009.

14. O'Dwyer G, Mattos RA. Teoria da estruturação de Giddens e os estudos de práticas avaliativas. Physis. 2010; 20(2):609-23.

15. Rodríguez C, Lamothe L, Barten F, Haggerty J. Gobernanza y salud: significado y aplicaciones en América Latina. Rev Salud Publica. 2010; 12(1):151-9. 
16. Organização Pan-americana de Saúde. Redes Integradas de Servicios de Salud: conceptos, opciones de política y hoja de ruta para suplementación en las Américas. Washington (DC): OPS; 2010.

17. Gawryszewski ARB, Oliveira DC, Gomes AMT. Acesso ao SUS: representações e práticas de profissionais desenvolvidas nas Centrais de Regulação. Physis. 2012; 22(1):119-40.

18. Mendes EV. As redes de atenção à saúde. Cienc Saude Colet. 2010; 15(5):2297-305.

Konder MT, O'Dwyer G. Integración de las Unidades de Atención de Emergencia (UPA) con la red sanitaria en el municipio de Rio de Janeiro, Brasil. Interface (Botucatu). 2016; 20(59):879-92.

En el municipio de Rio de Janeiro, la implementación de las Unidades de Atención de Emergencia (UPA) fue principio rector de la política de salud y modelo para la estructuración de la red de emergencia (RUE). Esta encuesta analizó la integración de las UPA con otros servicios de salud. Fueran realizadas nueve entrevistas con los gerentes centrales y locales, interpretadas según la Teoría de la Estructuración de Anthony Giddens. Los resultados mostraron poca integración de las UPA, causadas por debilidades estructurales de la red y por la fragmentación de la gestión de los servicios. A pesar de la inversión política y financiera, esta estrategia no ha logrado superar los problemas de integración entre los servicios de salud, señalando la baja prioridad que el gobierno coloca para la atención primaria y el poco desarrollo de las redes de atención a la salud.

Palabras clave: Servicios Médicos de Urgencia. Atención a la Salud. Administración de los Servicios de Salud.

Submetido em 20/07/15. Aprovado em 15/03/16. 